\title{
AFTER-EFFECTS OF GEOMAGNETIC STORMS: STATISTICAL ANALYSIS AND THEORETICAL EXPLANATION
}

\section{K.G. Ratovsky}

Institute of Solar-Terrestrial Physics SB RAS, Irkutsk, Russia,ratovsky@isz.irk.ru

\section{M.V. Klimenko}

West Department of Pushkov Institute of Terrestrial Magnetism, Ionosphere and Radio Wave Propagation RAS, Kaliningrad, Russia, maksim.klimenko@mail.ru Immanuel Kant Baltic Federal University, Kaliningrad,Russia,maksim.klimenko@mail.ru

\section{V.V. Klimenko}

West Department of Pushkov Institute of Terrestrial Magnetism, Ionosphere and Radio Wave Propagation RAS, Kaliningrad,Russia,vvk_48@mail.ru

\author{
N.V. Chirik \\ West Department of Pushkov Institute of Terrestrial \\ Magnetism, Ionosphere and Radio Wave Propagation RAS, \\ Kaliningrad,Russia,wsaad@mail.ru \\ Immanuel Kant Baltic Federal University, \\ Kaliningrad, Russia,wsaad@mail.ru \\ N.A. Korenkova \\ Immanuel Kant Baltic Federal University, \\ Kaliningrad, Russia,ninakoral@gmail.com \\ D.S. Kotova \\ West Department of Pushkov Institute of Terrestrial \\ Magnetism, Ionosphere and Radio Wave Propagation RAS, \\ Kaliningrad, Russia,darshu@yandex.ru \\ Immanuel Kant Baltic Federal University, \\ Kaliningrad, Russia,darshu@yandex.ru
}

\begin{abstract}
Our previous studies have shown the presence of daytime positive electron density disturbances during several days after the start of the recovery phase. The aim of this paper is to study after-effects of geomagnetic storms (after-storm effects), i.e. ionospheric effects observed on the $3-5^{\text {th }}$ day after the beginning of the storm recovery phase. From numerical calculations with the GSM TIP model, we have found the main mechanisms for the formation of the after-storm effects. Using Irkutsk $\left(52^{\circ} \mathrm{N}, 104^{\circ} \mathrm{E}\right)$ and Kaliningrad $\left(54^{\circ} \mathrm{N}\right.$, $20^{\circ} \mathrm{E}$ ) ionosonde data, we have carried out a statistical analysis of daytime ionospheric responses to geomagnetic storms. As a result of the analysis, we obtained averaged ionospheric responses at the beginning of the storm recovery phase and for five consecutive days. The statistical analysis results received near the beginning of the recovery phase are in good agreement with the wellknown ionospheric effects of geomagnetic storms ob-
\end{abstract}

tained in previous studies. For the first time, the obtained statistics of ionospheric responses observed on the $3-5^{\text {th }}$ day after the beginning of the recovery phase allowed us to reveal the dependence of after-storm ionospheric effects on season, storm intensity, and ionosonde geomagnetic latitude. In addition, we for the first time present the interpretation of after-storm ionospheric effects from numerical simulation results.

Keywords: geomagnetic storm, after-storm ionospheric effects, statistics, GSM TIP model.

\section{INTRODUCTION}

When studying ionospheric responses to geomagnetic storms, the disturbances observed during the storm main phase are generally analyzed because they are the most intense during this period [Buonsanto, 1999; Mendillo, 2006; Prölss, 1995, 2008]. Negative electron density disturbances in the F-region during early recovery phase of geomagnetic storms are one of the most studied phenomena [Prölss, 1995], whereas positive ionospheric disturbances during the geomagnetic storm recovery phase are the least explored area of the upper atmosphere response to geomagnetic storms, which has been studied only for the last five years [Klimenko et al., 2015; Balan et al., 2013; Suvorova et al., 2013]. The behavior of the ionosphere at the late recovery phase and after a geomagnetic storm has practically not been investigated. Model calculations and observations of ionospheric effects of geomagnetic storms on Septem- ber 26, 2011 (Dst=-118 nT) and March 17, 2015 (Dst=-223 nT) have, however, shown the presence of sufficiently strong positive electron density disturbances observed during the daytime on the 3-5th day after the beginning of the geomagnetic storm recovery phase [Klimenko et al., 2015; Klimenko et al., 2017, 2018]. Hereafter, the daytime ionospheric effects observed on the 3-5th day after the beginning of the recovery phase are called after-storm effects.

Calculations of upper atmosphere parameters [Klimenko et al., 2015; Klimenko et al., 2017, 2018], made using the Global Self-Consistent Model of the Thermosphere, Ionosphere and Protonosphere (GSM TIP) [Namgaladze et al., 1990; Klimenko et al., 2006; Korenkov et al., 1998], have shown that the main cause of positive after-storm effects is an increase in the ratio of atomic oxygen to molecular nitrogen $n(\mathrm{O}) / n\left(\mathrm{~N}_{2}\right)$. This result was unexpected since the well-known effect 
in the geomagnetic storm recovery phase is an opposite effect - a decrease in $n(\mathrm{O}) / n\left(\mathrm{~N}_{2}\right)$, hence a negative electron density disturbance [Prölss, 1995]. In fact there is no contradiction between the GSM TIP calculation results and the generally accepted concepts: the negative disturbance of $n(\mathrm{O}) / n\left(\mathrm{~N}_{2}\right)$ is characteristic of the storm main phase and the first days of the recovery phase, whereas the positive disturbance of $n(\mathrm{O}) / n\left(\mathrm{~N}_{2}\right)$ is characteristic of the end of the recovery phase and the afterstorm effect. Thus, the $n(\mathrm{O}) / n\left(\mathrm{~N}_{2}\right)$ disturbance as well as the electron density disturbance, like pendulum oscillations, passes from the negative phase to the positive phase within a few days after the beginning of the storm recovery phase. Mechanisms for the formation of afterstorm effects are analyzed in detail in the next section.

The previous results [Klimenko et al., 2015; Klimenko et al., 2017, 2018] offered no insight into the question of whether the after-storm effects characterize the September 26, 2011 and March 17, 2015 geomagnetic storms or they are typical of all geomagnetic storms. To answer this question, we have developed a special method of statistical analysis of ionospheric responses to geomagnetic storms, which is based on Irkutsk $\left(52^{\circ} \mathrm{N}, 104^{\circ} \mathrm{E}\right)$ and Kaliningrad $\left(54^{\circ} \mathrm{N}, 20^{\circ} \mathrm{E}\right)$ ionosonde data.

Thus, the paper addresses the following tasks: a) detailed analysis of the mechanisms for the formation of after-storm effects; b) development of a method of statistical analysis of ionospheric responses to geomagnetic storms; c) study of the after-storm effects on the basis of the obtained statistics of ionospheric responses to geomagnetic storms.

\section{MECHANISMS FOR THE FORMATION OF AFTER-STORM EFFECTS}

Since after-storm effects are daytime effects, in this and the following sections we analyze daytime (averaged in the interval 10-14 LT) disturbances of ionospheric and thermospheric parameters. The disturbances are considered to be deviations of the parameters from the values computed for quiet conditions in the model calculations; and the deviations from the median values (27-day moving medians) in the observations.

For the peak electron density $N_{\mathrm{m}} \mathrm{F} 2$, atomic oxygen $n(\mathrm{O})$ and molecular nitrogen $n\left(\mathrm{~N}_{2}\right)$ densities, we use the relative percentage deviations $\left(\delta N_{\mathrm{m}} \mathrm{F} 2, \delta n(\mathrm{O})\right.$, and $\left.\delta n\left(\mathrm{~N}_{2}\right)\right)$; and for the meridional thermospheric wind $V_{\mathrm{n}}$, we use the absolute deviations from quiet values $\left(\Delta V_{\mathrm{n}}\right.$ in $\left.\mathrm{m} / \mathrm{s}\right)$. The subject of the analysis is the dynamics of disturbances in the 6-day interval: day 0 is the beginning of the storm recovery phase; and days $1, \ldots, 5$, the next five days.

Figure 1 shows the dynamics of $N_{\mathrm{m}} \mathrm{F} 2$ disturbances from the GSM TIP calculations and the observations over Irkutsk and Kaliningrad for the September 26, 2011 and March 17, 2015 magnetic storms. The Figure indicates that for almost all days of the storms we have obtained qualitative agreement between model calculations and observations. The agreement between calculations and observations improves as the time interval from
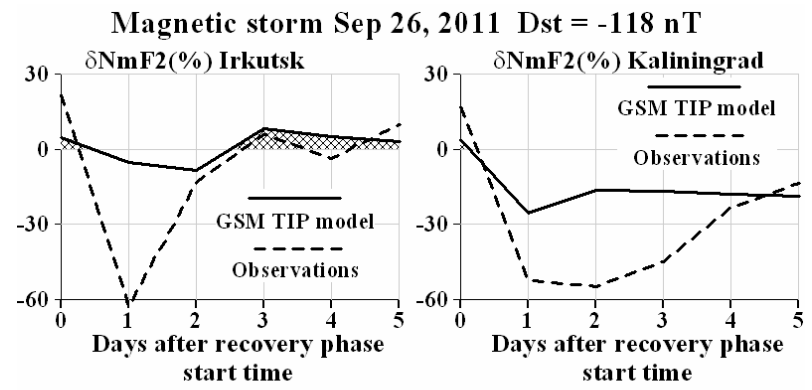

Magnetic storm Mar 17, 2015 Dst $=-223$ nT
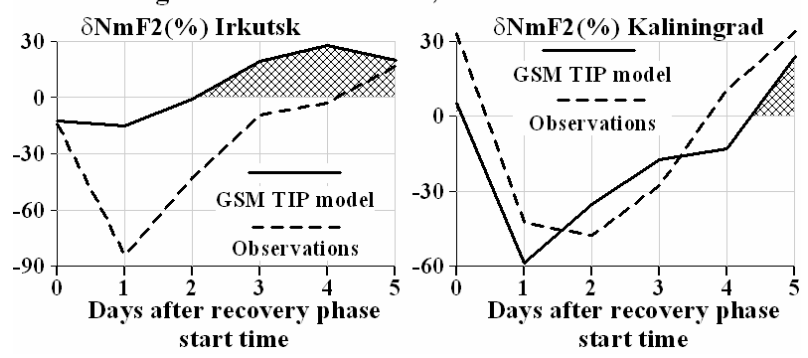

Figure 1. Dynamics of $N_{\mathrm{m}} \mathrm{F} 2$ disturbances within five days after the beginning of the recovery phase as derived from GSM TIP calculations (solid curves) and observations (dashed curves) over Irkutsk (left) and Kaliningrad (right) for the magnetic storms of September 26, 2011 (top) and March 17, 2015 (bottom). Crosshatched areas are intervals of positive disturbances according to model calculations

the end of the storm active phase increases. On the $3-5$ th day after the beginning of the recovery phase, we can see quantitative agreement between the after-storm effects according to the model calculations and observations. It should be noted that on the 1 st and 2 nd days after the beginning of the recovery phase the calculations do not quantitatively reproduce the observed $N_{\mathrm{m}} \mathrm{F} 2$ disturbances over Kaliningrad and Irkutsk (the model seriously underestimates the amplitude of the negative $N_{\text {m }}$ 2 disturbances). The possible reasons are low accuracy and simplified specification of such input parameters of the model as the cross-polar cap potential difference, polar cap boundary location, magnitude and location of the region 2 field-aligned currents, as well as the use of the climatological model of auroral precipitation, and hence a fairy high degree of their uncertainty. This does not allow us to accurately describe the real dynamics and spatial structure of changes in the parameters of the coupled thermosphere-ionosphere system in terms of electrodynamic processes during a geomagnetic disturbance. It is also important to note that considerable negative disturbances during geomagnetic storms observed at some mid-latitude stations in the daytime are poorly reproducible effects in most studies carried out using self-consistent models. The reason for this lies in the changes of ionization sources and losses (in our opinion, mainly the latter) during geomagnetic storms. To obtain just the neutral atmosphere composition changes which led to the actually observed ionospheric disturbances, it is necessary to conduct quite substantive studies because there may be fairly many reasons for the discrepancies between calculations and observations: a) insufficient and sometimes not entirely correct consideration of the vibrationally excited molecular nitrogen; 
b) incomplete consideration of the heating of the highlatitude and auroral ionosphere by precipitation and Joule heating due to the mentioned above uncertainty.

Three of the four panels (Figure 1) demonstrate the clear transition of the $N_{\mathrm{m}} \mathrm{F} 2$ disturbances from the negative phase to the positive one when, in fact, the positive afterstorm effects occur. Note that this dynamics of $\delta N_{\mathrm{m}} \mathrm{F} 2$ is characteristic of both the model calculations and the observations. In one of the four $N_{\mathrm{m}} \mathrm{F} 2$ disturbances (Kaliningrad, the September 26, 2011 storm), positive after-storm effects are not realized. This is again typical of both the model calculations and the observations. Possible reasons for the absence of the positive after-storm effects are discussed later in this section.

To determine the causes for the after-storm effect (transition of the $N_{\mathrm{m}} \mathrm{F} 2$ disturbances from the negative phase to the positive one), we have analyzed $\delta n(\mathrm{O})$, $\delta n\left(\mathrm{~N}_{2}\right)$, and $\Delta V_{\mathrm{n}}$ variations at a height of $250 \mathrm{~km}$, obtained from the GSM TIP calculations. Figure 2 shows the dynamics of $n(\mathrm{O})$ and $n\left(\mathrm{~N}_{2}\right)$ disturbances obtained by GSM TIP.

The dynamics of $n\left(\mathrm{~N}_{2}\right)$ disturbances is similar for both the storms at both the stations: on the first day after the beginning of the recovery phase (day 1 ), the positive disturbance peaks and then decreases. In one of the four cases (Irkutsk, the September 26, 2011 storm), the $n\left(\mathrm{~N}_{2}\right)$ disturbances become negative. The behavior of the $n(\mathrm{O})$ disturbances is somewhat different for the two stations. In Irkutsk, $\delta n(\mathrm{O})$ is generally positive, with the maximum disturbance on the third day after the beginning of the recovery phase (day 3). In Kaliningrad for the March 17, 2015 storm, $\delta n(\mathrm{O})$ monotonically increases from the second day (day 2) after the beginning of the recovery phase and peaks on the fifth day (day 5). For the September 26, 2011 storm, $\delta n(\mathrm{O})$ monotonically decreases from the early recovery phase. The after-storm effect (transition of the $N_{\mathrm{m}} \mathrm{F} 2$ disturbance from the negative phase to the positive one) over Kaliningrad and Irkutsk for March 17, 2015 occurs when $\delta n(\mathrm{O})$ is equal to $\delta n\left(\mathrm{~N}_{2}\right)$. For the September 26 , 2011 storm in Irkutsk, the after-storm effect occurs when $\delta n(\mathrm{O})$ peaks and $\delta n\left(\mathrm{~N}_{2}\right)$ becomes negative. Thus, the analysis of $\delta n(\mathrm{O})$ and $\delta n(\mathrm{~N} 2)$ variations shows that the cause of the after-storm effect is the increase in $n(\mathrm{O})$ against the decrease in $n\left(\mathrm{~N}_{2}\right)$; this leads to the formation of a positive disturbance in $n(\mathrm{O}) / n\left(\mathrm{~N}_{2}\right)$ and hence in $N_{\mathrm{m}} \mathrm{F} 2$. In the absence of positive dynamics in $n(\mathrm{O})$ (Kaliningrad, the September 26, 2011 storm) there is no afterstorm effect.

Figure 3 displays the dynamics of the $V_{\mathrm{n}}$ disturbances obtained by GSM TIP. The positive $V_{\mathrm{n}}$ disturbance means an equatorward wind enhancement (causing an increase in $N_{\mathrm{m}} \mathrm{F} 2$ ); and the negative disturbance, a poleward wind enhancement (causing a decrease in $N_{\mathrm{m}} \mathrm{F} 2$ ). Figure 3 indicates that in the after-storm effect phase the wind disturbances (both positive and negative) are minor (less than $10 \mathrm{~m} / \mathrm{s}$ ), so they do not substantially affect the $N_{\mathrm{m}} \mathrm{F} 2$ disturbance. Nevertheless, in the March 17, 2015 storm, wind disturbances strengthen the positive $N_{\mathrm{m}} \mathrm{F} 2$ disturbance, which occurs due to the increase in $n(\mathrm{O}) / n\left(\mathrm{~N}_{2}\right)$; and in the September 26, 2011

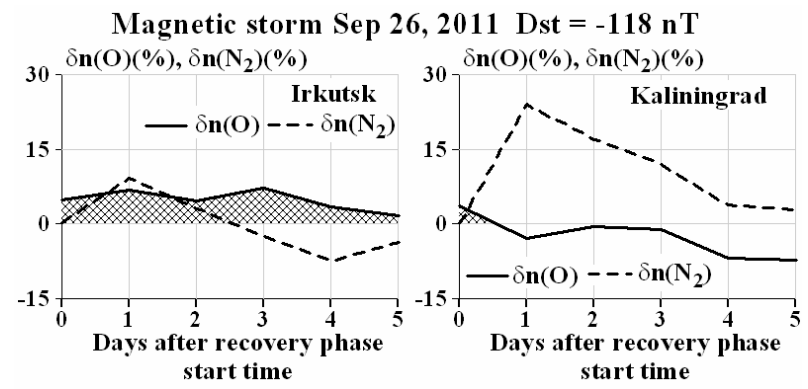

Magnetic storm Mar 17, 2015 Dst $=-223$ nT
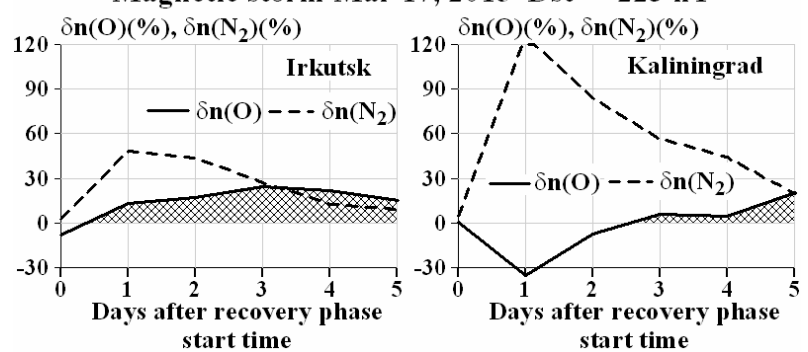

Figure 2. Dynamics of disturbances of $n(\mathrm{O})$ (solid curves) and $n\left(\mathrm{~N}_{2}\right)$ (dashed curves) according to GSM TIP calculations over Irkutsk (left) and Kaliningrad (right) for the magnetic storms of September 26, 2011 (top) and March 17, 2015 (bottom). Crosshatched areas are the intervals of positive $n(\mathrm{O})$ disturbances
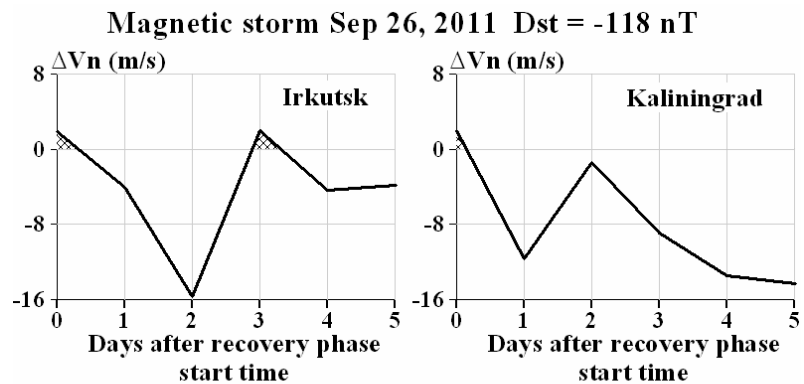

Magnetic storm Mar 17, 2015 Dst $=-223 \mathrm{nT}$
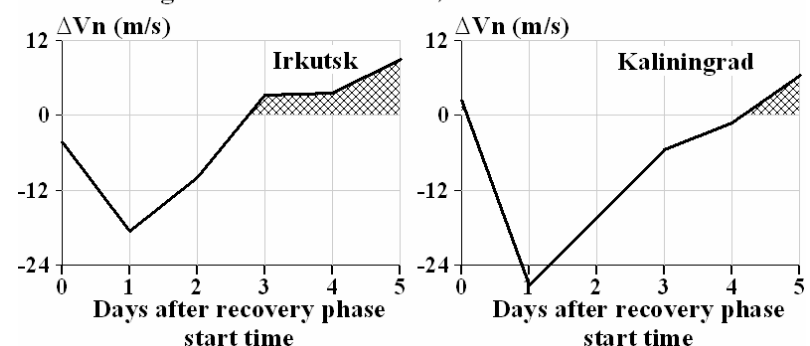

Figure 3. Dynamics of $V_{\mathrm{n}}$ disturbances as derived from GSM TIP calculations over Irkutsk (left) and Kaliningrad (right) for the magnetic storms of September 26, 2011 (top) and March 17, 2015 (bottom). Crosshatched areas are intervals of positive $V_{\mathrm{n}}$ disturbances

storm, weaken it. It is important to note that after the strong geomagnetic storm of March 17, 2015, the behavior of the wind disturbances at both the stations is similar. At the beginning, the poleward wind is formed due to the increase in the neutral density at low latitudes. Then there is an opposite effect likely associated with the inertia of the entire system of the upper atmosphere. This leads to an increase in the neutral density at higher latitudes. 
Figure 4 presents a scheme explaining the main mechanisms for the formation of disturbances of $N_{\mathrm{m}} \mathrm{F} 2$, atomic oxygen and molecular nitrogen densities in the storm main phase and after-storm effect phase. The part of the scheme that demonstrates processes in the upper atmosphere at the initial stage and in the main phase of the geomagnetic storm is a generalization and a modification of the schemes and results presented in [Brunelli, Namgaladze, 1988; Mayr et al., 1978]. During the storm main phase, the lower thermosphere heats up at auroral latitudes due to the Joule heating increase and auroral precipitation enhancement. This causes both molecular nitrogen and atomic oxygen densities in the upper thermosphere to rise and neutral particles to be transported from high to middle and equatorial latitudes. The number of neutral particles transported to the lower latitudes depends on the intensity and duration of the geomagnetic storm main phase. The transport of molecular nitrogen as a heavier gas covers auroral and subauroral latitudes. The transport of atomic oxygen as a lighter gas covers all latitudes up to the equatorial ones.

An increase in the neutral gas density at equatorial latitudes is an additional effect, which causes the neutral temperature to go down and, consequently, the molecular nitrogen density to decrease in the upper thermosphere. As a result, in this storm phase due to the change in the neutral composition, $n(\mathrm{O}) / n\left(\mathrm{~N}_{2}\right)$ and $N_{\mathrm{m}} \mathrm{F} 2$ decrease (compared to quiet conditions) at auroral
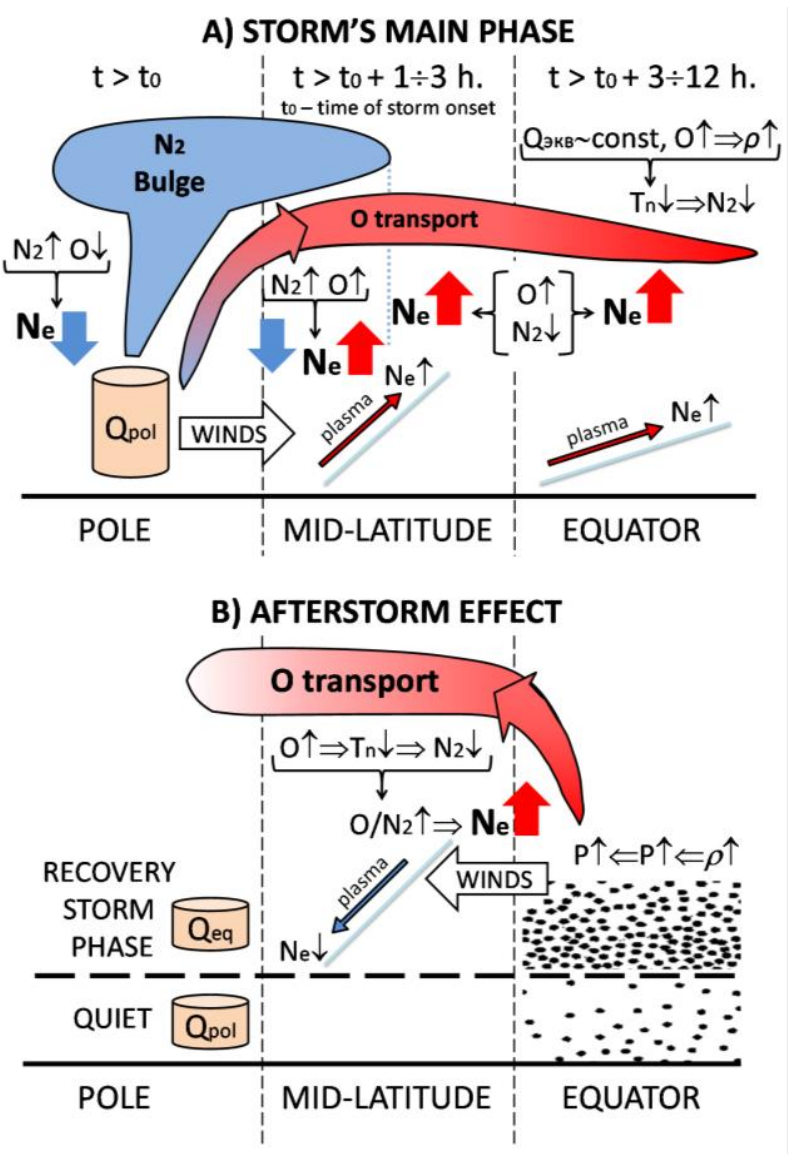

Figure 4. Scheme explaining the main mechanisms for the formation of disturbances of atomic oxygen and molecular nitrogen densities, as well as electron density in the F-region during the storm main phase $(a)$ and after-storm effect phase $(b)$ and subauroral latitudes [Brunelli, Namgaladze, 1988; Mayr et al., 1978], and $n(\mathrm{O}) / n\left(\mathrm{~N}_{2}\right)$ and $N_{\mathrm{m}} \mathrm{F} 2$ increase at low, subequatorial, and middle latitudes [Klimenko et al., 2011; Danilov, 2013; Field, Rishbeth, 1997; Mayr et al., 1978]. Daytime positive $N_{\mathrm{m}} \mathrm{F} 2$ disturbances, generated by the equatorward thermospheric wind (the most effective at midlatitudes) and the effects of the horizontal and vertical $\mathrm{E} \times \mathrm{B}$ plasma drift are also superimposed on these disturbances [Tashchilin, 2014; Krinberg, Tashchilin, 1984; Brunelli, Namgaladze, 1988]. Plasma transport does not, however, produce noticeable effects in the after-storm effect phase, and therefore we do not examine it in detail.

In the after-storm effect phase due to the higher neutral gas density at equatorial and low latitudes, there appears an additional poleward pressure gradient, and there is a process which is opposite to that taking place during the geomagnetic storm main phase: atomic oxygen is transported from equatorial latitudes to middle and auroral latitudes, thus leading to an increase in $n(\mathrm{O})$ at these latitudes. The increase in the neutral gas density at middle and auroral latitudes is an additional effect, which decreases temperature and hence the molecular nitrogen density in the upper thermosphere.

As a result, in the after-storm effect phase we can expect an increase (compared to quiet conditions) in $n(\mathrm{O}) / n\left(\mathrm{~N}_{2}\right)$ and $N_{\mathrm{m}} \mathrm{F} 2$ in the latitudinal region encompassing either equatorial, middle, and subauroral latitudes or equatorial and some middle latitudes. The location of the high-latitude boundary of this spatial region depends on the latitudinal gradient of neutral density resulting from a geomagnetic storm, on conditions of the atomic oxygen transport from low to higher latitudes, and on the residual positive disturbance of $n\left(\mathrm{~N}_{2}\right)$. In this case, the latitudinal range of occurrence of the after-storm effect, as well as the occurrence of this effect per se, should depend on many factors such as season, intensity, and duration of a geomagnetic storm, longitude, solar activity, etc.

\section{METHOD OF STATISTICAL ANALYSIS OF IONOSPHERIC RESPONSES TO GEOMAGNETIC STORMS}

Identification of geomagnetic storms with the use of a database of geomagnetic indices has been realized through the following algorithm. An event is considered a magnetic storm when the following conditions are met:

1) $D s t\left(t_{0}\right)$ is the lowest Dst in the time interval $t_{0} \pm$ $\pm 12 \mathrm{hrs}$

2) $\operatorname{Dst}\left(t_{0}\right) \leq-50 \mathrm{nT}$,

where $t_{0}$ is the time corresponding to the end of the main phase and to the beginning of the recovery phase of a geomagnetic storm. We have divided all storms into four groups: isolated (the time interval between adjacent storms $t_{0} \geq 5$ days); non-isolated (the said interval is less than 5 days); weak (Dst $\left.\left(t_{0}\right)>-100 \mathrm{nT}\right)$, and strong $\left(\operatorname{Dst}\left(t_{0}\right) \leq-100 \mathrm{nT}\right)$. In each group, we classified the storms according to seasons: winter (DecemberFebruary); spring (March-May); summer (JuneAugust), and fall (September-November). 
The statistics of daytime ionospheric responses to geomagnetic storms was calculated by the following method. As disturbances of the F2-layer electron density $\left(\Delta N_{\mathrm{m}} \mathrm{F} 2\right)$ we took deviations (in \%) of observed values $\left(N_{\mathrm{m}} \mathrm{F} 2_{\text {obs }}\right)$ from 27 -day moving medians $\left(N_{\mathrm{m}} \mathrm{F} 2_{\text {med }}\right)$ :

$$
\Delta N_{\mathrm{m}} \mathrm{F} 2=\left(N_{\mathrm{m}} \mathrm{F} 2_{\text {obs }}-N_{\mathrm{m}} \mathrm{F} 2_{\text {med }}\right) / N_{\mathrm{m}} \mathrm{F} 2_{\text {med }} \cdot 100 \% \text {. }
$$

To analyze the daytime ionospheric disturbances, we calculated daily average (10-14 LT) $\Delta N_{\mathrm{m}} \mathrm{F} 2$. The calculations were made for the day corresponding to $t_{0}$ (day 0 ) and for the next five days (day $1, \ldots, 5$ ).

For each cell corresponding to a given type of storm, season, and day after $t_{0}$, we calculated average values of $\Delta N_{\mathrm{m}} \mathrm{F} 2\left(<\Delta N_{\mathrm{m}} \mathrm{F} 2>\right)$, root-mean-square deviations $\sigma N_{\mathrm{m}}$ $\mathrm{F} 2$, and $R=<\Delta N_{\mathrm{m}} \mathrm{F} 2>/ \sigma N_{\mathrm{m}} \mathrm{F} 2$. The parameter $R$ is an analogue of the signal-to-noise ratio, which indicates the ratio of the deterministic component of the process (in this case, the average value) to the random component of the process (in this case, the root-mean-square deviation).

The analyzed Irkutsk ionosonde data cover the period 2003-2016. The period comprises 291 magnetic storms (98 isolated, 193 non-isolated, 249 weak, and 42 strong storms). The analyzed Kaliningrad ionosonde data cover the period 1964-2016 (with a gap from 1997 to 2006) and include 1808 magnetic storms (684 isolated, 1124 non-isolated, 1489 weak, and 319 strong storms). We do not discuss the influence of solar activity on the ionospheric effect of magnetic storms in this paper.

\section{RESULTS OF STATISTICAL ANALYSIS AND THEIR DISCUSSION}

Figure 5 shows variations in the ratio $R$ within five days after the beginning of the recovery phase for isolated and non-isolated storms in Irkutsk and Kaliningrad. The same for weak and strong storms is depicted in Figure 6.

\section{The beginning of the recovery phase (days 0-2)}

The recovery phase is generally characterized by the presence of systematic negative $N_{\mathrm{m}} \mathrm{F} 2$ disturbances (negative $R$ ). The negative $N_{\mathrm{m}} \mathrm{F} 2$ disturbances are caused by the heating of the lower thermosphere in auroral latitudes, an increase in molecular nitrogen density in the upper thermosphere, and the transport of the disturbed neutral component to midlatitudes. Both for Irkutsk and for Kaliningrad, the largest absolute negative values of $\mathrm{R}$ are observed in summer; and the smallest ones (positive in Irkutsk), in winter.

Such a picture perfectly fits the well-known concept [Buonsanto, 1999; Mikhailov, 2000; Prölss, 1993] of the seasonal dependence of the ionospheric response to geomagnetic storms. The background daytime poleward wind prevents the penetration of the disturbed neutral component from high to middle latitudes, thus reducing negative effects of geomagnetic storms. In winter, the daytime wind is stronger than in summer, so the effect of weakening the negative disturbances is more pronounced. The daytime-wind weakening per se leads to positive effects, which are more pronounced in winter due to the stronger wind effect on the electron density than in summer. The fact that the positive effects in the

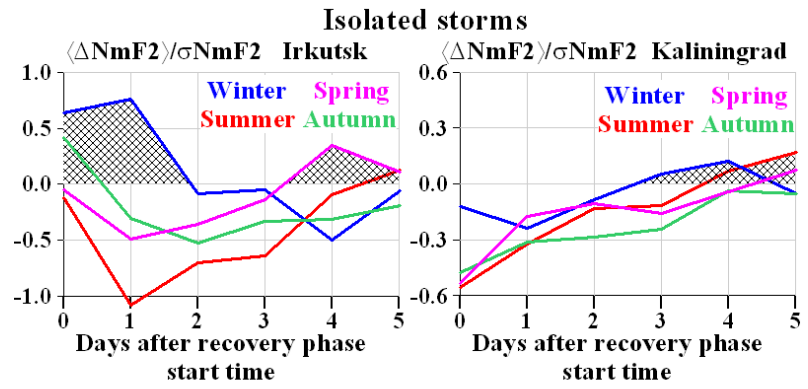

NonIsolated storms

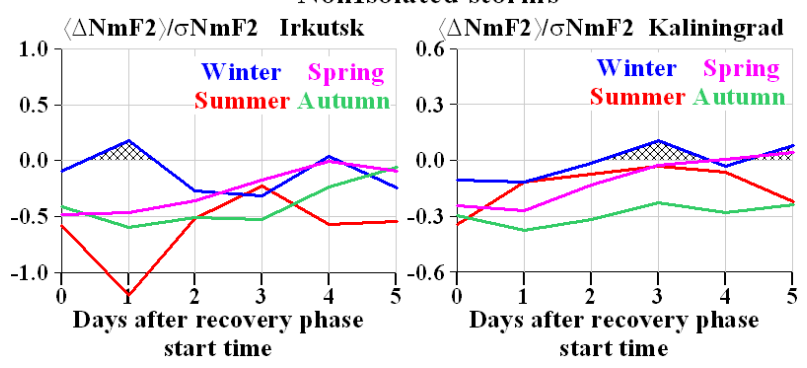

Figure 5. Variations in the ratio $R$ within five days after the beginning of the recovery phase for isolated (top) and nonisolated (bottom) storms in Irkutsk (left) and Kaliningrad (right). Blue, purple, red, and green curves show the results obtained for winter, spring, summer, and fall, respectively. Crosshatched areas are intervals of positive $<\Delta N_{\mathrm{m}} \mathrm{F} 2>/ \sigma N_{\mathrm{m}} \mathrm{F} 2$

Weak storms Dst $>-100 \mathrm{nT}$
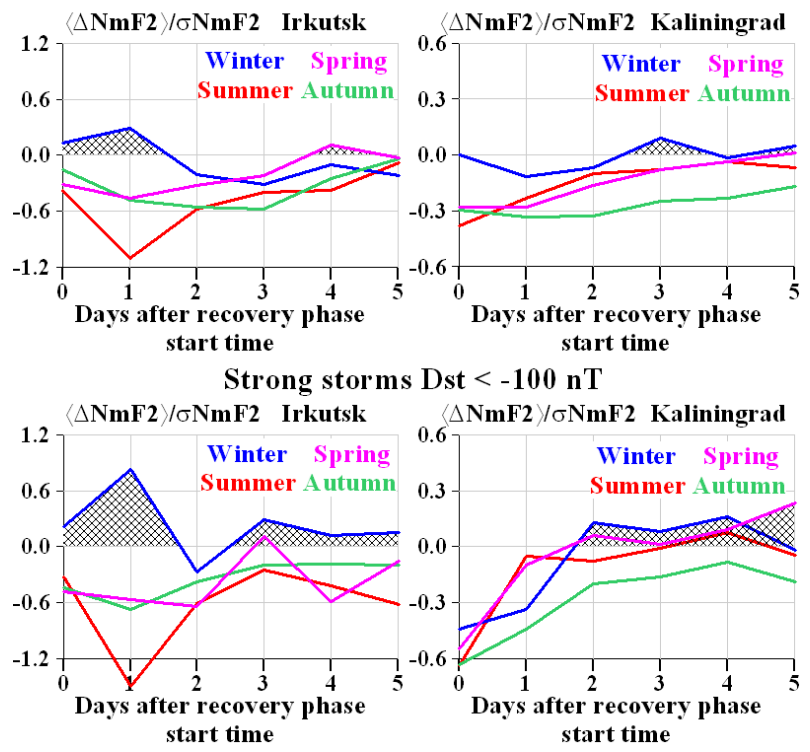

Figure 6. The same as in Figure 5 for weak and strong storms

early recovery phase are observed only in Irkutsk can probably be explained by the higher geomagnetic latitude of Kaliningrad and hence by a closer position relative to the neutral component disturbance sources at auroral latitudes.

\section{After-storm effect phase (days 3-5)}

Unlike the early recovery phase, the similarities and differences between Kaliningrad and Irkutsk in the after-storm effect phase are not so obvious. The greatest positive effect in both the cases occurs in spring, but in Irkutsk it is seen for isolated magnetic storms; whereas in Kaliningrad, for strong magnetic 
storms. Also noteworthy are the marked positive effects in summer for isolated magnetic storms in Kaliningrad and in winter for strong magnetic storms in Irkutsk. Thus, a common feature for both the stations is that positive after-storm effects are most noticeable in isolated or strong magnetic storms. In non-isolated magnetic storms, the early recovery phase effects are superimposed on the after-storm effects, thus neutralizing the positive effects in the after-storm effect phase. In weak magnetic storms, the after-storm effects are likely to be much less pronounced than in strong storms. This is consistent with the results of model calculations (Figure 1), which indicate that after-storm effects are more pronounced in more severe storms.

Another common feature for both the stations is that in the after-storm effect phase the greatest positive effects never occur in fall; and the greatest negative effects, in spring. Thus, in contrast to the early recovery phase, the opposite seasonal effects occur in spring and fall, not in winter and summer. On the one hand, this feature is consistent with the results of model calculations (Figure 1), which suggest that after-storm effects are more pronounced in the spring storm than in the fall one. On the other hand, as mentioned above, the differences can be explained by the fact that the fall storm was weaker than the spring one (Figure 1). Thus, the problem of theoretical justification of the fact that the most favorable conditions for positive af ter-effects of geomagnetic storms exist in spring is still unsolved. It should again be noted that the previous model calculations of ionospheric responses to magnetic storms [Klimenko et al., 2015; Klimenko et al., 2017, 2018] have shown that a positive after-storm effect can be observed both in fall and in spring.

\section{Ratio of deterministic component to random component of ionospheric response}

The ratio $R$ indicates how large the average afterstorm effect is relative to the random distribution of $N_{\mathrm{m}} \mathrm{F} 2$ variations. Referring to Figures 5 and 6 , this ratio is small: in the early recovery phase, $R$ is of the order of 1 ; and in the after-storm effect phase, $R$ does not exceed 0.35 . The random component of ionospheric response is due to the interaction of the processes generated by a magnetic storm with the processes associated with solar and atmospheric activity of all types. For example, the results obtained by Pedatella [2016] demonstrate a comparable role of the effects of the extreme geomagnetic storm and the strong sudden stratospheric warming in 2009. Such a behavior of the ionospheric response complicates the statistical analysis, particularly in the after-storm effect phase, where storm effects are noticeably weaker than in the early recovery phase. Nevertheless, the statistical results for the early recovery phase are consistent with the well-known concept of the seasonal dependence of the ionospheric response to geomagnetic storms. As for the after-storm effect phase, it requires further research involving both the simulation and the improvement of the method of statistical analysis. In any case, this paper has reported the first statistical results which provide insight into the origin of daytime positive ionospheric effects observed on the 3-5th day after the beginning of the geomagnetic storm recovery phase.

\section{CONCLUSION}

The purpose of this paper was to study the positive electron density disturbances observed during the daytime on the 3-5th day after the beginning of the geomagnetic storm recovery phase, which we called after-storm effects.

Using GSM TIP numerical calculations, we have analyzed the main mechanisms for the formation of the after-storm effects. It has been shown that the main cause of the observed positive electron density disturbances is an increase in the atomic oxygen density due to its transport from equatorial to middle latitudes in the after-storm effect phase. In turn, this transport is caused by the additional neutral gas pressure gradient from low to high latitudes, which arises from the appearance of the excess neutral gas density at low latitudes in the geomagnetic storm main phase due to the equatorward transport of oxygen from auroral latitudes.

Using data from Irkutsk $\left(52^{\circ} \mathrm{N}, 104^{\circ} \mathrm{E}\right)$ and Kaliningrad $\left(54^{\circ} \mathrm{N}, 20^{\circ} \mathrm{E}\right)$ ionosondes, we have carried out a statistical analysis of daytime ionospheric responses to geomagnetic storms. The main results are as follows. The statistics near the beginning of the recovery phase is consistent with the known effects of geomagnetic storms. The statistics that has been obtained for the first time allowed us to determine two main features:

1) positive after-storm effects are most noticeable in isolated or strong geomagnetic storms;

2) the most favorable season for positive afterstorm effects is spring; and the least favorable, fall.

The former feature is explained by the absence of superposition of negative effects, formed in the early recovery phase, on after-storm effects for isolated storms, and by the fact that in weak magnetic storms after-storm effects are much less pronounced than in strong storms. This is consistent with the results of model calculations. The problem of theoretical justification of the latter feature is still unsolved.

The statistical analysis has shown that the ratio of the deterministic component to the random component of the ionospheric response in the early recovery phase is about 1; and in the after-storm effect phase, it does not exceed 0.35 . The random component of the ionospheric response is due to the interaction between the processes caused by a magnetic storm per se and the processes associated with atmospheric activity of all types. Thus, the study of the ionospheric effects in the after-storm effect phase requires further efforts involving both model calculations and improvement of the method of statistical analysis.

This study (model calculations and their analysis, statistical processing of observations) was funded by the Russian Foundation for Basic Research under research project No. 18-05-00594. The results were obtained using the equipment of Center for Common Use «Angara» [http://ckp-rf.ru/ckp/3056]. Experimental data and data processing methods were obtained with budgetary funding of Basic Research program II.12. The work with the Kaliningrad ionosonde database was carried out under the Program «5-100» for Improving Competitiveness at IKBFU. We are grateful to NASA's Space Physics Data Facility (SPDF) for providing access to the database of geomagnetic indices [http://omniweb.gsfc. nasa.gov/form/dx1.html]. 


\section{REFERENCES}

Brunelli B.E., Namgaladze A.A. Fizika ionosfery [Physics of the ionosphere]. Moscow, Nauka Publ., 1988, 528 p. (In Russian).

Buonsanto M.J. Ionospheric storms: a review. Space Sci. Rev. 1999, vol. 88, no. 3-4, pp. 563-601. DOI: 10.1023/A: 1005107532631.

Balan N., Otsuka Y., Nishioka M., Liu J.Y., Bailey G.J. Physical mechanisms of the ionospheric storms at equatorial and higher latitudes during the recovery phase of geomagnetic storms. J. Geophys. Res. 2013, vol. 118, pp. 2660-2669. DOI: 10.1002/jgra.50275.

Danilov A.D. Reaction of $\mathrm{F}$ region to geomagnetic disturbances (review). Geliogeofizicheskie issledovaniya [Heliogeophys. Res.]. 2013, no. 5, pp. 1-33. (In Russian).

Field P.R., Rishbeth H. The response of the ionospheric F2-layer to geomagnetic activity: an analisys of wordwide data. J. Atmos. Solar-Terr. Phys. 1997, vol. 59, no. 2, pp. 163 180. DOI: 10.1016/S1364-6826(96)00085-5.

Klimenko V.V., Klimenko M.V., Bryukhanov V.V. Numerical simulation of the electric field and zonal current in the Earth's ionosphere - problem statement and test calculations. Mathematical Models and Computer Simulations. 2006, vol. 18, no. 3, pp. 77-92. (In Russian).

Klimenko M.V., Klimenko V.V., Ratovsky K.G., Goncharenko L.P. Ionospheric effects caused by the series of geomagnetic storms of September 9-14, 2005. Geomagnetism and Aeronomy. 2011, vol. 51, no. 3, pp. 364-376. DOI: 10.1134/S00 16793211030108.

Klimenko M.V., Klimenko V.V., Bessarab F.S., Ratovsky K.G., Zakharenkova I.E., Nosikov I.A., Stepanov A.E., Kotova D.S., Vorobjev V.G., Yagodkina O.I. Influence of geomagnetic storms of September 26-30, 2011, on the ionosphere and $\mathrm{HF}$ radiowave propagation. I. Ionospheric effects. Geomagnetism and Aeronomy. 2015, vol. 55, no. 6, pp. 744-762. DOI: 10.1134/S0016793215050072.

Klimenko M.V., Klimenko V.V., Zakharenkova I.E., Ratovsky, Korenkova N.A., Yasyukevich Yu.V., Mylnikova A.A., Cherniak Iu.V. Similarity and differences in morphology and mechanisms of the $f_{\mathrm{o}} \mathrm{F} 2$ and TEC disturbances during the geomagnetic storms on 26-30 September 2011. Ann. Geophys. 2017, vol. 35, pp. 923-938. DOI: 10.5194/angeo-35-923-2017.

Klimenko M.V., Klimenko V.V., Despirak I.V., Zakharenkova I.E., Kozelov B.V., Cherniakov S.M., Andreeva E.S., Tereshchenko E.D., Vesnin A.M., Korenkova N.A., Gomonov A.D., Vasiliev E.B., Ratovsky K.G. Disturbances of the thermosphere - ionosphere - plasmasphere system and auroral electrojet at $30^{\circ} \mathrm{E}$ longitude during the St. Patrick's Day geomagnetic storm on 17-23 March 2015. J. Atmos. Solar-Terr. Phys. 2018. DOI: 10.1016/j.jastp.2017.12.017. (In print).

Korenkov Y.N., Klimenko V.V., Forster M., Bessarab F.S., Surotkin V.A. Calculated and observed ionospheric parameters for Magion-2 passage above EISCAT on July 31 1990. J. Geophys. Res. 1998, vol. 103, no. A7, pp. 14,697-14,710. DOI: 10.1029/98JA00210.

Krinberg I.A., Tashchilin A.V. Ionosfera $i$ plazmosfera [Ionosphere and Plasmasphere]. Moscow, Nauka, 1984, 129 p. (In Russian).

Mayr H.G., Harris I., Spencer N.W. Some properties of upper atmosphere dynamics. Rev. Geophys. Space Phys. 1978, vol. 16, pp. 539-565. DOI: 10.1029/RG016i004p00539.

Mendillo M. Storms in the ionosphere: Patterns and processes for total electron content. Rev. Geophys. 2006, vol. 44, RG4001. DOI: 10.1029/2005RG000193.

Mikhailov A.V. Ionospheric F2-layer storms. Fisica de la Tierra. 2000, vol. 12, pp. 223-262.

Namgaladze A.A., Korenkov Yu.N., Klimenko V.V., Karpov I.V., Bessarab F.S., Surotkin V.A., Glushchenko T.A., Naumova N.M. Global numerical model of the Earth's ther- mosphere, ionosphere and protonosphere. Geomagnetism and Aeronomy. 1990, vol. 30, no. 4, pp. 612-619. (In Russian).

Pedatella N.M. Impact of the lower atmosphere on the ionosphere response to a geomagnetic superstorm. Geophys. Res. Lett. 2016, vol. 43, iss. 18, pp. 9383-9389. DOI: 10.1002/ 2016GL070592.

Prölss G.W. On explaining the local time variation of ionospheric storm effects. Annales Geophysicae. 1993, vc ${ }^{1}$ 11, no. 1, pp. 1-9.

Prölss G.W. Ionospheric F-region storms. Handbook oJ Atmospheric Electrodynamics. 1995, pp. 195-248.

Prölss G.W. Ionospheric storms at mid-latitudes: a short review. Midlatitude Ionospheric Dynamics and Disturbances. 2008, pp. 9-24. (Geophys. Monograph Ser., vol. 181). DOI: $10.1029 / 181 \mathrm{GM} 03$.

Suvorova A.V., Dmitriev A.V., Tsai L.-C., Kunitsyn V.E., Andreeva E.S., Nesterov I.A., Lazutin L.L. TEC evidence for near-equatorial energy deposition by $30 \mathrm{keV}$ electrons in the topside ionosphere. J. Geophys. Res. 2013, vol. 118, pp. 46724695. DOI: $10.1002 /$ jgra.50439.

Tashchilin A.V. Formirovanie krupnomasshtabnoi struktury ionosfery $v$ spokoinykh $i$ vozmushchennykh usloviyakh [Formation of large-scale structure of the ionosphere in quiet and disturbed conditions. Dr. Phys. \& Math. Sci. Diss.]. Irkutsk, 2014, 236 p. (In Russian).

URL: https://www.esrl.noaa.gov/psd (accessed September 8, 2018).

URL: https://www.esrl.noaa.gov/psd (accessed September 8, 2018).

How to cite this article

Ratovsky K.G., Klimenko M.V., Klimenko V.V., Chiric N.V., Korenkova N.A. Kotova D.S. After-effects of geomagnetic storms: statistical analysis and theoretical explanation Solar-Terrestrial Physics. 2018. Vol. 4. Iss. 4. P. 26-32. DOI: 10.12737/stp-44201804. 